\title{
Ueber das bittere Princip des gemeinen Wermuths
}

\author{
rom \\ Apotheker Mein \\ in Neustadt Gödens.
}

Das bittere Princip des Wermuths (Artemisia Absinthium L.) isolirt darzustellen, sind schon die Herren Leon a rdi zu Poveredo (Brandes Archir Bd.XXVIII S. 2ii) und Carentov (Braades Archiv Bd. XXIX S. 167) bemüht gewesen. Es ist ibnen dies jedoch nur theilweise geglücht.

Herr Leonardi bebandelte Werinuthextract mit Alkohol von $36^{\circ} \mathrm{B}$. so lange, bis dieser sich nicht mehr färbte. Die klaren geistigen Auszüge wurden bis auf $1 / 4$ abdestillirt, der Rüchstand zur Syrupsdiche abgeraucht und nit Wasser behandelt, wodnrch sich ein harziger Niederschlag absonderte, welcher mit warmem Wasser ausgew aschen warde, bis diese geschmacklos ablief. Zu dur wăsserigen Flüssigkeit wurde nun so lange saure schwefelsaure Alannerde gesetzt, bis der Niederschlag, welcher augenblicklich entatand, sich gelb zu färben begans. Dann warde die Flüssigheit abfiltrirt, zor Trockne verdunstet, der Rückstand in Alkohol aufgelöst, und die Autlösung zur Extractdicke gobracht.

Auf diese - Weise zerfiel das Wermuthextract in: ein geschmaclloses Gummi, eine harzige in kohlensaurem Hali löslicbe Substanz und in ein sehr bitteres, hygroscopisches, in Wasser und Alkohol lösliches Extract. Dies so bereiteto Extract batte sich gegen intermitticeade Fieber sehr wirksam gezeigt.

Ferner fand Herr Caventou, dafs in einem wässerigen Wermuthinfusum durch essigsaures Blei ein starker Nieder. schlag herrorgebracht und die Flüssigkeit gänzlich entfarbt ward, olsne die Bitterheit zu verlieren. Der in Wasser zer. 
theilte und durch einen Strom Hydrothionsäure zersetzte Bleiniedersehlay gab ein von Bitterheit freies Product, daher das bittere Princip mit dem überschüssigen essigsauren Blei in der Flüssigkcit muste gelüst geblieben seyn. Nachdem dicse Flüssigkeit von dem Bleigehalt durch Hydrothionsāure war befreit worden, gab sie nach dem Filtriren und Abrauchen bis zur gehörigen Consistenz, eine braune, fettige, sehr bittere Haterie, woraus sich ein weifses Salz mit mineralischer Base ohne Bitterkeit abschied. Alkobol mit 1/3 Aether vermengt, entzog derselben die Bitterteit, und diese Lösung gab durch freiwilliges Verdunsten bleine Raniticationen einer braunen, brüchigen, sehx bittern Substanz, ohne bestimmte Form, welche Substanz Caventou für das bittere Princip hielt.

Meinen wiederholi darüber angesteliten Versuchen und gemachten Erfahrungen zufolge, ist das in dem Wermuth extracte enthaltene Harz (? d. R.) der alleinige 'Iräger der Bitterkeit desselben und es ist demnach Hr. Carentou der Wahrbeit sehr nahe gekommen.

In des. Darstellung des Harzes bin ich gewissermalseo dem Herm Leonardi gcholgt, nur dafs ich dabei noch fïr ein sehr frisches Extract Sorge trug. Es wurden nämlich s2 Unzen der kurz zuvor geernteten and schnell getmocknetem Blätter und blühenden Spitzen des Wermuths, sebr fein zerschnitten, mit so vicl warmen Wasser begossen, als sie einzusaugen vermuchten, nach 24 Stunden stark ausgeprefst und Jiest Extraction noch ein- bis zweimal wiederbolt. Die durchgeseiheten Flüssigkeiten im Wasssrbade, gegen das Ende der Arbeit sehr vorsichtig, zur Syrupdicke gebracht, wurde aus dem. 8 Unzen betragenden Extracte, auf obige Wcise unittelst Alkohol das Harz gewonnen.

Da nan aber die Muttchlauge, woraus das eben fällbare Harz dunch Wasser niedergeschlagen worden, ferner auf 
Harz noch benutzen mufs, weil die Ausbeute sonst sehr gering ausfallen dürfte, so stöfst man nach einigen Niederschlagungen bald auf eine so invige Mischung von Extractivstoff, etwas Schleimzuclier und Harz, dafs Alkolsol oder Wasser sie gleich gut aufnebmen. Das bittere hygroscopische Extract des Herrn J,eonardi ist wahrsckeinlich eine solche Mischung mit noch etwas Schwefelsüure.

Um jene innige Mischung zu zersetzen, war ich gezwun$g^{e n}$, aus einer alhoholischen Lösung derselben den Extractivstoff und Zucker mit Aether zu fällen, urn durch Verdunsten der Flüssigkeit bis zur Trocline und Aufweichen des Rücketandes mit Wasser, das Harz zu gewinnen.

Die gesammelten Antbeile ron Harz bedurften noch einer Reinigung, um es von dem ihm fest anhärgenden Extractivstoff wu befieien. Zu dem Ende wurde es in seinem drei- bis vierfachen Gewicht alkohol golöst, diese Auflosung nach und nach bis zur g̈inzlichen Fällung des Iarzes mit Wasser versetat und der Weingeist durch Verdunsten estfernt. Dies Auflösen und Fällen des Ilarzes mufs recht oft und so lange wiedesholt werlen, his die Mutterlauge - nach gänzlicter Entferaung des Weingeistes - durch die Auflösung des salzsauren Eisenoxydes micht mehr grün oder grünlich, sondern bräunlicbgeth getiübt wird. Ist dieser Punkt erreicht, kann man das IJarz als ganz frei ron Extractivatoff betrachten,

Die obigen in Arbeit genomnienen $8: 9$ Unzen trocknen Firautes gaben mir zwei Brachmen und einco Scrupel eines solchen Harzes.

Aus frischem Kraute bereitet, besitzt es die Farbe and Sprödigkeit des gowöhnlieben Jalappenharzes; aus älterem, lange der Luft ausgesetzt geweseren Hrante dorgestellt, er-" schieint es viel dunkler und ist weniger suröds. Aus der

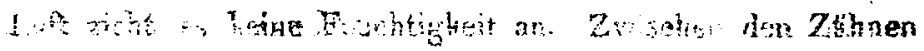


klebt es bald an und hinterläfst dabei an der Zungenspitze pin Gefïh von Sebärfe und Wärme. Fs ist so concentrirt bitter, dals ein Gran, in ein praar Drachmen Weingeist ge löst und mit 125 Unzen $=60,000$ Granen $W$ asser vermischt, demselhen eine moh sebr bemerkbare Bitterteit mittheilt. Die geistige sowohl als auch die concentrirte wässerige $I, 00-$ sung dieses Harzes röthet das Lackmus.

Um es möglichst farblos darzustellen, wurde ein Scrupel in einer Unze Weingeist ron 80 Gew. pr. C. gelöst, diese Jösung zu tier Unżen Weingeist yon 3o Gew. pr. S. gegossen, durch Schütteln gemischt, a4 Stunden in Ruhe gestellt und der abgclagerte flochige Niudersclilag durch Filtriren getrennt. Der llaren Flïssiglieit wurde nun so lange eine verdïnnte Lüsung ron Bleizucher unter abwechoelndem Sohüttcin angefügt, bis cine hleise abfiltrirte Probe durch Zusaty. von rerdünnter Schwefelsäure eine Spur überschússigen Blei's zu erkennen gab. Die statk getrübte Flüssigheit wurde in einer Abdampfocbale mit 4 Unacn Wasser permischt and so lange einer sebr. gelinuen Wärene asogesetzt, bis der Weingeist vollstäudig vorllüchtigt war. Prach dem Frkalten wurde filtrirt und so lange ein Strom vin Sebwifelwasserstoffgas durch die Flïssigkrit geleitet, bis nach starkem Schütteln die Flüssigleit bald sich hlärte und mit Schwefelwasserstoffgas vollständig gesättigt war. Durch Erwärmen in einer Schale nurde das Schwefthasserstoffgas eotfernt; das nicht. selten rülblichbraun gefürbte Schwefelblei nahm dabei baid spine eigenthümliche Farbe an, und die vorher manchmal schwarh weingelb gefirbte Flüssigkeit war zugleich dadurch entfitbs. Dic durch Filtriren rom Schwefelblei befreite Flüssigheit wurde nun in einer Schalt einer gelinden Wärme bis zu $50^{\circ}$ R. zum Verdunsten ausgesetzt. Sie bedechte sich bald mil einer farblosen Haut, und bei einiger Concentration bildeten sich auf dem boden der Schale während der 
Wärme - Eiowirkung Wleine undeutlich sïulenfürmige, fast weifse Krystalle. Nachdem die auf der Flüssigkeit gebildete Haut an die Seite geschoben und die Mutterlauge abgegossen war, um nach dem Austrocknen die Krystalle, deren größster Theil am Hoden der Schale festsafs, durch $\Lambda$ bschaben gewin. nen zu tönnen, wurden durch ferneres Einengen der Flüssigkeit selten noch Krystalle erhalten, und wenn einmal, so waren sie mehr gefärbt and verworren abgelagert. Der letzte Gehalt an Harz sctjied sich vielmehr in der Form einer Haut auf der Oberfläche ab, die zurückgeschoben bald durch eine neu sich bildende ersetzt wurde. Dabei zeigte die Luft eine merkliche Einwirkung anf dasselbe, denn wenn die erste Haut anfangs auch farblos war, so waren es die folgenden immer weniger; sie wurden gelblich und zuletzt scbmutzig braungelb.

Ein Scrupel des bräunlichen Harzes gab nur 4 Gran jener Hrystalle. Dies hautförmig abgeschiedene Harz getrock. net, mit Glaspulver vermengt und mit Aether übergossen, durch Schütteln die Aullösung befördert, dann nach einiger Rube in ein Schälchen abgegossen, hinterliefs nach dem freiwilligen Verdunsten an der Luft. und dem gänzlichen Aus. trocknen, einen fast farblosen firuifsartigen Ueberzag, der das gereinigte Harz darstellt.

Das vorzüglichste Auflösungsmittel des gereinigten Wermathharzes ist der Weingeist, dann folgt der Aether, und vom Wasser erfordert das frisch bereitete Harz mebr als tausend Theile zur hlaren Aullösung. Durch lange Einwirkung der Luft wird das Harz auflülicher in Wasser. Die concentrirte wässerige milchartige Harzlösung - die ich mir dadurch rerschaffte, dafs ich einige Tropfen einer geistigen Lösung desselben mit Wasser vermischte und den Weingeist durch Verdunsten entfernte - röthet das Lackmuspapies. Von den gewöhnlichen Reagentien, die mir nur zu Gebou

Anal. a Pbarra. Bul Via. Heft*. 
standen, bringt - im verdünnten Zustande derselben :heins einen Niederschlag darin hervor als nur der Gallöpfelaufunts.

Ton den sehr verdünnteu lösungen der ätzenden und kohlensäucrlichen Alkalien wird das gereinigte Wermuthharz anfgelöst und diese Auflösung wird durch Verdïnnung nicht getrübs.

Dagegen bewirken alte concentrirten wässerigen Lösungen von Säuren, Alhalien, Metall - und anderen leichtlöslichen Salzea, mit der conoentrirten wässerigen llarzlösung anssanmengebracht, eine käsige Abschcidung desselben.

Dis trookne feste Hars, mit der concentrirten Schwefelsän in Berührung gebracht, theilt dieser eine intensiv gelbe Farbe mit, die nach und nach in ein dunkles Purpus übergeht. Die concentrirte Salpetersäure löst es ebenfalls langsam 2k einer gethen trüben Flüssigheit auf. Die con. ceatrirte Salzsäure wird dadurch gebräunt. Auch die Essiy. näure lïst das Wernuthlare leicht auf und aus dieser Aullösung wird durch Wasser das Horz wieder ahgeschiedan.

In einer Clasröhre langsam erhitzl, wird es flässig, bräurs sich dann und unter Fntwickelung eines brenzlish rlechenden Damples, der onfangs sich za braunen Tröpfohen verdichtet, denen dunkelgriin getärbte folgen; wird es verbohlt*).

-) Herr Apotlieher Mein. hatte die Güte, uns cine hleine Probe des hier beschriebenen Vermuthstoffs mitzutheiten, welches nach einigen Versuchen, die' ich damit anstellte. die bemerkten Eigenschaften besitzt: namentlich ist der bittere Geschmack -esselben aufserordentiich und anhaltend t.).

Br.

f) Harz möchte ich übrigens diesen Stoff nicht nesinen Es ist wahrscheinlich ein 'srystallicirbarer stichstohfreicr Stoff, dem Santonil nahe steherid, der zu den sogenannten (stickstoftfrcten) Bitterstofiarten gehört. 